\title{
Pengaruh Kecerdasan dan Minat Pribadi Sosial terhadap Penyesuaian Diri Mahasiswa Bimbingan dan Konseling
}

\author{
Nina Permata Sari*, Ririanti Rachmayanie Jamain \\ Program Studi Bimbingan dan Konseling, Fakultas Keguruan dan Ilmu Pendidikan, Universitas Lambung Mangkurat, \\ J1. Brigjen H. Hasan Basri, Banjarmasin, Kalimantan Selatan, Indonesia 70123 \\ *Penulis koresponden, e-mail: nina.bk@ulm.ac.id
}

Artikel diterima: 26 Februari 2019; direvisi: 14 Mei 2019; disetujui: 16 Mei 2019

\begin{abstract}
The objective of this research is to identify the influence of intelligence and social self interest on the adaptation skill of the department of guidance and counseling students. This quantitative research used the multiple regression analysis. It used purposive total sampling technique, with sample of 38 students of Department of Guidance and Counseling, Faculty of Teacher Training and Education, Universitas Lambung Mangkurat (ULM). The results show that intelligence and social self interest of the department of guidance and counseling students simultaneously influence the adaptation skill of $35.9 \%$, while the remaining $64.1 \%$ is influenced by other factors.
\end{abstract}

Keywords: intelligence; personal social interests; college students' self-adjustment

\begin{abstract}
Abstrak: Tujuan penelitian ini adalah untuk mengetahui pengaruh kecerdasan dan minat pribadi sosial terhadap penyesuaian diri mahasiswa jurusan bimbingan dan konseling. Penelitian kuantitatif ini menggunakan teknik analisis regresi berganda. Teknik sampling menggunakan teknik purposive total sampling, dengan sampel berjumlah 38 orang mahasiswa Jurusan Bimbingan dan Konseling, Fakultas Keguruan Ilmu Pendidikan (FKIP), ULM. Hasil menunjukkan kecerdasan dan minat pribadi sosial mahasiswa jurusan bimbingan dan konseling secara bersama-sama memengaruhi penyesuaian diri sebesar $35,9 \%, 64,1 \%$ sisanya dipengaruhi oleh faktor lain.
\end{abstract}

Kata kunci: kecerdasan; minat pribadi sosial; penyesuaian diri mahasiswa

\section{PENDAHULUAN}

Perbedaan latar belakang pendidikan dan asal daerah menyebabkan penyesuaian diri mahasiswa di perguruan tinggi menjadi beragam. Keragaman tersebut dapat berbentuk kecerdasan maupun minat pribadi sosial yang mampu memengaruhi penyesuaian diri individu. Penyesuaian diri berhubungan dengan kemampuan individu untuk menghadapi perubahan, mempertemukan tuntutan dalam diri dan lingkungan agar tercapai tujuan yang diharapkan (Lusiawati, 2013). Manusia tidak akan terlepas dari proses penyesuaian diri karena penyesuaian diri terus terjadi di sepanjang fase perkembangan kehidupan (Agustina, 2018). Fase perkembangan ini berupa perkembangan fisik; sosial; emosi; nilai moral; kognitif; dan kepribadian.

Penyesuaian diri berhubungan erat dengan perkembangan sosial karena berhubungan dengan kematangan hubungan atau interaksi sosial individu dengan norma masyarakat dan agama (Yusuf LN \& Sugandhi, 2011). Artinya, penyesuaian diri berkaitan dengan kemampuan individu untuk menjalin interaksi sosial yang baik dengan masyarakat dan agama. Hal ini menyebabkan penyesuaian diri sebagai suatu proses yang bersifat dinamis karena menuntut harmonisasi individu dengan lingkungan sosial individu dan segala keunikannya. Individu merupakan makhluk yang unik dan memiliki keragaman kebutuhan (Desmita, 2011). Keunikan dan keragaman kebutuhan pribadi ini membutuhkan kemampuan beradaptasi dengan lingkungan sosial, agar individu mampu menyesuaikan diri dengan baik.

Cara mengutip: Sari, N. P., \& Jamain, R. R. (2019). Pengaruh Kecerdasan dan Minat Pribadi Sosial terhadap Penyesuaian Diri Mahasiswa Bimbingan dan Konseling. Jurnal Kajian Bimbingan dan Konseling, 4(2), 75-80. https://doi.org/10.17977/um001v4i22019p075 
Remaja akhir sering kali mengalami permasalahan terkait penyesuaian diri (Boynton-Jarrett dkk., 2012; Schoon dkk., 2004; Webster-Stratton dkk., 2011). Nisa (2017) dalam penelitiannya menemukan bahwa masa remaja akhir usia 18-21 tahun membutuhkan kematangan hubungan dengan teman seusianya, memerankan peran sosialnya sebagai wanita atau pria dewasa secara tepat; efektif; dan menjalankan nilai serta norma sosial secara bertanggungjawab. Masa remaja akhir terjadi pada mereka yang telah memasuki perkuliahan atau mahasiswa dan dituntut untuk lebih bertanggungjawab terhadap diri dan sosial. Mahasiswa sering kali mengalami kesulitan dalam penyesuaian diri (Farkhaeeni, 2011), terutama mahasiswa baru yang mengalami persoalan akademik dan non-akademik (Nurfitriana, 2016). Kesulitan beradaptasi juga dipengaruhi oleh teman sebaya dan motivasi (Iflah \& Listyasari, 2013)

Data dari hasil laporan tes psikologi oleh Unit Layanan Bimbingan dan Konseling (ULBK) FKIP ULM tahun ajaran 2018-2019 menunjukkan hampir 30\% mahasiswa jurusan bimbingan dan konseling FKIP ULM memiliki penyesuaian diri yang masuk pada kategori rendah dan sangat rendah, hal ini perlu untuk diidentifikasi. Identifikasi dianggap perlu karena sebagai dasar ULBK FKIP ULM merancang dan membuat program layanan pada mahasiswa. Selain itu, identifikasi juga dilakukan untuk memperoleh informasi tentang faktor-faktor yang terbukti berpengaruh terhadap penyesuaian diri mahasiswa, yang mana faktor tersebut dapat dikembangkan dan diarahkan. Siklus umum penyesuaian diri mahasiswa adalah di awal memasuki perkuliahan, mahasiswa melakukan pengamatan; menjalin hubungan baik dengan teman; dan mengikuti perubahan yang terjadi di lingkungan kampus (Zubaidi, 2016). Selama proses ini, mahasiswa akan diiringi dengan konflik personal, seperti: frustasi; rasa bersalah; dan kecemasan. Namun, jika mahasiswa mampu mengarahkan kecerdasannya dengan tepat, maka mahasiswa akan mampu mengembangkan dirinya dengan baik, seperti memperoleh: prestasi; rajin; hati-hati dalam mengambil keputusan; tumbuh kepercayaan diri; mendapat dukungan dari teman; dan memiliki hubungan baik dengan keluarga.

Kecerdasan memiliki peranan penting dalam memengaruhi kemampuan individu melakukan penyesuaian diri, hal ini dikarenakan daya pikir membantu individu untuk memilih dan mengambil keputusan secara tepat bagi diri dan lingkungannya (Ali \& Asrori, 2005). Selain itu, kecerdasan merupakan sumber bagi individu untuk dapat berpikir secara rasional, menilai kondisi, permasalahan dan keterbatasan yang dimiliki agar dapat diselaraskan sesuai dengan keadaan yang sebenarnya dan mengarahkan individu untuk bersikap realistik serta objektif. Kecerdasan dapat membantu individu untuk memecahkan masalah-masalah sosial secara tepat dan objektif. Ketika individu mampu menggunakan kecerdasannya untuk memecahkan masalah sosial secara tepat dan objektif, berdasarkan pengambilan keputusan yang baik, maka individu dapat menyesuaikan diri dengan baik pula.

Penyesuaian diri, tidak hanya dipengaruhi oleh kecerdasan yang dimiliki oleh individu, namun ada faktor lain yang dinilai memberikan sumbangan pengaruh, yaitu minat individu untuk melakukan interaksi sosial (Handono \& Bashori, 2013; Kumalasari \& Ahyani, 2012). Individu yang memiliki minat dan bakat dalam dirinya, dinilai lebih mampu menjalin hubungan baik dengan lingkungan dan mampu beradaptasi dengan kondisi yang baru (Difa, 2016). Hasil penelitian lain menunjukkan bahwa individu yang memiliki minat, salah satunya minat sosial, akan terdorong untuk melakukan aktivitas sosial yang dapat memberikan penghargaan bagi dirinya dari masyarakat dan terpandang secara terhormat (Suharyat, 2009). Beberapa hasil penelitian tersebut menunjukkan bahwa minat mampu memberikan dorongan yang lebih pada diri individu untuk melakukan suatu tindakan yang bermanfaat bagi individu. Guna menumbuhkan penyesuaian diri yang baik pada mahasiswa, maka penanaman minat dalam diri mahasiswa perlu ditumbuhkan.

Penyesuaian diri berperan penting bagi individu untuk mengatasi konflik; ketegangan; dan kebutuhan dalam dirinya agar tuntutan dalam diri dengan lingkungan mampu selaras dan harmonis (Desmita, 2011). Artinya, mahasiswa membutuhkan penyesuaian diri untuk membantunya mengatasi konflik dan mencapai keharmonisan antara tuntutan dalam diri dengan lingkungan. Untuk mencapai hal tersebut remaja membutuhkan kecerdasan dan minat dalam dirinya. Tujuan penelitian ini adalah untuk mengkaji tentang pengaruh kecerdasan dan minat individu terhadap penyesuaian diri mahasiswa bimbingan dan konseling. 


\section{METODE}

Penelitian ini dimaksudkan untuk mengetahui pengaruh kecerdasan dan minat pribadi sosial terhadap penyesuaian diri mahasiswa jurusan bimbingan dan konseling. Variabel bebas 1 (X1) adalah kecerdasan dan variabel bebas 2 (X2) adalah minat pribadi sosial, sedangkan variabel terikat (Y1) adalah penyesuaian diri. Populasi penelitian adalah mahasiswa jurusan bimbingan dan konseling FKIP ULM angkatan 2016. Teknik pengambilan sampel menggunakan teknik purposive total sampling, Sampel dalam penelitian ini adalah 38 mahasiswa jurusan bimbingan dan konseling FKIP ULM angkatan 2016. Pertimbangan pemilihan teknik ini karena mahasiswa jurusan bimbingan dan konseling angkatan 2016 akan segera menyelesaikan studi. Instrumen yang digunakan dalam penelitian ini adalah: (1) Culture Fair Intelligence Test (CFIT) yang digunakan untuk mengukur variabel kecerdasan; (2) Tes Minat Jabatan Lee-Thorpe yang digunakan untuk mengukur variabel minat pribadi sosial; dan (3) Edwards Personal Preference Schedule (EPPS) yang digunakan untuk mengukur variabel penyesuaian diri. Data yang diperoleh dari hasil pengukuran, kemudian diadaptasi ke dalam Skala Likert. Teknik analisis data dalam penelitian ini menggunakan analisis regresi sederhana.

\section{HASIL}

Sebagai persyaratan analisis data, peneliti melakukan sejumlah pengujian berupa: uji normalitas; uji heteroskedastisitas; dan uji multikolinieritas. Hasil uji normalitas menunjukkan nilai signifikan 0,862 $>0,05$, artinya nilai residual berdistribusi normal. Namun, berdasarkan analisis diketahui bahwa hasil toleransi adalah 0,997 $>0,10$ yang artinya tidak terjadi multikolinearitas. Kenyataan lain pada hasil analisis, diketahui hasil signifikan X1 (kecerdasan) sebesar 0,308 >0,05, yang berarti tidak terjadi heteroskedastisitas. Kemudian dari hasil analisis, dapat diketahui hasil signifikan X2 (minat pribadi sosial) sebesar 0,399 >0,05. Sehingga dari analisis data diketahui pada variabel kecerdasan, minat pribadi sosial dan penyesuaian diri tidak terjadi heteroskedastisitas pada setiap variabelnya.

\section{Pengaruh Kecerdasan terhadap Penyesuaian Diri}

Hasil analisis menunjukkan nilai adjusted $R$ square adalah 0,287 , hal ini berarti kecerdasan (X1) memberikan pengaruh sebesar $28,7 \%$ terhadap variabel penyesuaian diri $(\mathrm{Y})$ dan sisanya sebesar 71,3 $\%$ dipengaruhi oleh faktor-faktor lain di luar variabel X1. Dari hasil uji signifikansi simultan, diperoleh nilai $F$ hitung 15,908 dengan probabilitas 0,000. Dikarenakan probabilitas lebih kecil dari 0,05, sehingga dapat dikatakan variabel kecerdasan (X1) berpengaruh terhadap variabel penyesuaian diri (Y).

Persamaan regresi dapat dijelaskan sebagai berikut: (1) konstanta sebesar 46,407 bermakna jika pengaruh variabel kecerdasan bernilai 0 , maka nilai variabel penyesuaian diri adalah 46,407 . Artinya, tanpa ada pengaruh variabel kecerdasan, estimasi variabel penyesuaian diri memiliki nilai konstan sebesar 46,407; (2) koefisien regresi variabel kecerdasan sebesar 0,474, artinya jika variabel kecerdasan mengalami kenaikan satu poin, maka penyesuaian diri akan mengalami kenaikan sebesar 0,474 poin. Koefisien bernilai positif, dimaknai bahwa ada pengaruh positif antara kecerdasan terhadap penyesuaian diri. Hipotesis alternatif (Ha) menjadi terbukti, bahwa ada pengaruh variabel kecerdasan terhadap variabel penyesuaian diri mahasiswa jurusan bimbingan dan konseling.

\section{Pengaruh Minat Pribadi Sosial terhadap Penyesuaian Diri}

Nilai adjusted $R$ square minat pribadi sosial (X2) sebesar 0,045. Artinya minat pribadi sosial (X2) memberikan pengaruh sebesar 4,5\% terhadap variabel penyesuaian diri (Y) dan sisanya, 95,5\% dipengaruhi faktor-faktor lain di luar variabel minat pribadi sosial. Variabel minat pribadi sosial berdasarkan hasil uji signifikansi simultan, diperoleh nilai $\mathrm{F}$ hitung 2,758 dengan probabilitas 0,000 . Dikarenakan probabilitas lebih kecil dari 0,05 , dapat dikatakan variabel minat pribadi sosial (X2) berpengaruh terhadap variabel penyesuaian diri (Y).

Persamaan regresi dimaksudkan sebagai berikut: (1) konstanta sebesar 127,867 yang bermakna jika pengaruh variabel minat pribadi sosial bernilai 0 , maka nilai variabel penyesuaian diri adalah 127,867 . Artinya, tanpa adanya pengaruh variabel minat pribadi sosial, estimasi variabel penyesuaian diri memiliki nilai konstan sebesar 127,867 dan kedua, koefisien regresi variabel kecerdasan sebesar 0,300. Artinya jika variabel minat pribadi sosial mengalami kenaikan satu poin, maka penyesuaian diri 
akan mengalami kenaikan sebesar 0,300 poin. Koefisien bernilai positif, artinya terjadi pengaruh positif antara minat pribadi sosial terhadap penyesuaian diri. Hal ini berarti hipotesis alternatif (Ha) terbukti, yaitu bahwa ada pengaruh variabel kecerdasan terhadap variabel penyesuaian diri mahasiswa jurusan bimbingan dan konseling.

\section{Pengaruh Kecerdasan dan Minat Pribadi Sosial secara Bersama-sama terhadap Penyesuaian Diri}

Hasil pengaruh secara bersama-sama dari variabel kecerdasan dan minat pribadi sosial terhadap penyesuaian diri diperoleh nilai adjusted $R$ Square sebesar 0,359, maknanya variabel kecerdasan (X1) dan variabel minat pribadi sosial (X2) sama-sama berpengaruh sebesar 35,9\% terhadap variabel penyesuaian diri $(\mathrm{Y})$ dan sisanya $64,1 \%$ dipengaruhi oleh faktor-faktor lain di luar dari variabel yang diteliti. Hasil uji signifikansi simultan, diperoleh nilai $\mathrm{F}$ hitung 11,379 dengan probabilitas 0,000 . Disebabkan probabilitas lebih kecil dari 0,05, dapat dikatakan bahwa variabel kecerdasan (X1) dan variabel minat pribadi sosial berpengaruh terhadap variabel penyesuaian diri (Y).

(1) konstanta sebesar 79,193 bermakna jika pengaruh variabel kecerdasan dan minat pribadi sosial bernilai 0 , maka nilai variabel penyesuaian diri adalah 79,193. Artinya, tanpa adanya pengaruh variabel kecerdasan dan minat pribadi sosial, estimasi variabel penyesuaian diri memiliki nilai konstan sebesar 79,193; (2) koefisien regresi variabel kecerdasan sebesar 0,487, artinya jika variabel kecerdasan mengalami kenaikan satu poin, maka penyesuaian diri akan mengalami kenaikan sebesar 0,487 poin. Koefisien bernilai positif, artinya terjadi pengaruh positif antara kecerdasan terhadap penyesuaian diri; dan (3) koefisien regresi variabel minat pribadi sosial sebesar 0,333 , artinya jika variabel minat pribadi sosial mengalami kenaikan 1 poin, maka penyesuaian diri akan mengalami kenaikan sebesar 0,333 poin. Koefisien bernilai positif berarti adanya pengaruh positif antara minat pribadi sosial terhadap penyesuaian diri. Nilai Sig. kecerdasan dan minat pribadi sosial sebesar $0,000<0,05$, dapat diketahui bahwa hipotesis alternatif $(\mathrm{Ha})$ terbukti, variabel kecerdasan dan variabel minat pribadi sosial secara bersama-sama memengaruhi variabel penyesuaian diri mahasiswa jurusan bimbingan dan konseling.

\section{PEMBAHASAN}

Hasil penelitian menunjukkan kecerdasan memberikan pengaruh $28,7 \%$ terhadap penyesuaian diri mahasiswa jurusan bimbingan dan konseling. Individu yang memiliki kecerdasan tinggi, mereka akan: mudah mencerna (Ates, 2019); merespons suasana hati secara tepat; mampu berkomunikasi secara tepat (Cherry dkk., 2013; Zhu dkk., 2016); memiliki empati yang baik (Abe dkk., 2018); mampu menyelesaikan persoalan-persoalan; menghormati dan menghargai pendapat orang lain; berinteraksi (Dewi dkk., 2016); serta mampu melihat segala sesuatu dari berbagai sudut pandang. Tentu kemampuan ini sangat dibutuhkan dalam proses penyesuaian diri, karena individu dituntut untuk mengatasi keteganganketegangan; frustasi; dan konflik yang dialaminya. Dengan demikian, individu mampu menyelaraskan tuntutan dalam dirinya dan tuntutan lingkungannya secara efiesien dan memuaskan (Desmita, 2011).

Pengaruh kecerdasan pada penyesuaian diri individu tidak terlepas dari pengaruh interaksi sosial yang secara generalis adalah dukungan sosial bagi mahasiswa dalam melakukan penyesuaian diri. Sebuah penelitian menyebutkan bahwa ada implikasi yang positif dari dukungan sosial terhadap penyesuaian diri mahasiswa (Estiane, 2015). Dampak yang terlihat dari temuan ini adalah peningkatan prestasi akademik yang signifikan pada 203 orang mahasiswa baru Universitas Airlangga angkatan 2013.

Hal ini sejalan dengan hasil penelitian lain yang menyatakan bahwa kecerdasan/inteligensi merupakan sumber kekuatan bagi individu dalam mengatur diri; mengembangkan gagasan; melakukan penilaian dan mengambil keputusan yang diperlukan dalam penyesuaian diri (Artha \& Supriyadi, 2013). Didukung pula dari hasil penelitian lain yang menunjukkan kecerdasan spiritual memberikan pengaruh efektif sebesar 34,8\% terhadap penyesuaian diri, apabila individu memiliki kecerdasan spiritual yang tinggi maka individu cenderung mampu memahami nilai-nilai moral, etika, menghargai dan tidak menyakiti orang lain dalam menjalin hubungan sosial (Prima \& Indrawati, 2018).

Variabel minat pribadi sosial memberikan pengaruh sebesar $4,5 \%$ terhadap penyesuaian diri mahasiswa jurusan bimbingan dan konseling. Minat dapat dikategorikan sebagai motivasi, dan ini merupakan struktur kepribadian pada individu (Hansen, 1984). Minat pribadi sosial bermakna ketertarikan individu pada bidang hubungan sosial dan memberikan pelayanan publik. Indikator dalam minat 
di antaranya adalah perasaan senang; ketertarikan; dan perhatian (Hansen, 1984). Sumbangan ketiga indikator tersebut dalam penyesuaian diri mahasiswa tidak terlalu besar, yaitu 4,5\%, diduga karena minat individu pada pribadi sosial sebatas hanya pada rasa ketertarikan, senang dan keinginan saja, belum sampai pada tahap diimplementasikan dalam bentuk sikap atau perilaku yang dapat membantu individu dalam proses penyesuaian dirinya.

Selanjutnya, hasil penelitian menunjukkan kecerdasan dan minat pribadi sosial berpengaruh terhadap penyesuaian diri sebesar $35,9 \%$ dan sisanya $64,1 \%$ dipengaruhi oleh faktor lain. Penyesuaian diri merupakan kompetensi yang wajib dimiliki oleh mahasiswa bimbingan dan konseling agar mereka kelak sebagai guru bimbingan dan konseling diharapkan mampu menjalin hubungan baik dengan peserta didik; orangtua/wali peserta didik; tenaga pendidik dan kependidikan serta masyarakat sekitar (Wibowo, 2019). Hal ini menunjukkan bahwa penyesuaian diri menjadi kompetensi penting bagi guru bimbingan dan konseling agar dapat menjalin interaksi yang harmonis dan sesuai dengan peserta didik; orangtua/ wali; tenaga pendidik; dan kependidikan serta masyarakat.

Hasil temuan penelitian ini kiranya dapat dikembangkan lebih lanjut untuk dapat meningkatkan kemampuan penyesuaian diri individu dengan melakukan jenis penelitian eksperimen; penelitian tindakan kelas; modul pengembangan dan penelitian-penelitian lainnya dengan variabel yang sama. Kelebihan penelitian ini adalah menggunakan instrumen tes yang sudah baku secara internasional sehingga uji reliabilitas dan validitasnya sudah teruji, antara lain CFIT untuk mengukur kecerdasan, Lee-Thorpe untuk mengukur minat jabatan, dan EPPS untuk mengukur penyesuaian diri. Kekurangan penelitian ini adalah jumlah sampel yang dilibatkan hanya berjumlah 38 orang, sehingga perlu diuji pada jumlah sampel yang lebih luas.

\section{SIMPULAN}

Hasil penelitian menunjukkan bahwa kecerdasan dan minat pribadi sosial sama-sama berpengaruh terhadap penyesuaian diri mahasiswa jurusan bimbingan dan konseling, walaupun masih ada faktor lain yang berpengaruh. Hal ini berarti semakin baik/tinggi kecerdasan dan minat pribadi sosial maka akan menjadikan penyesuaian diri mahasiswa jurusan bimbingan dan konseling akan semakin baik/tinggi pula.

\section{DAFTAR RUJUKAN}

Abe, K., Niwa, M., Fujisaki, K., \& Suzuki, Y. (2018). Associations between Emotional Intelligence, Empathy and Personality in Japanese Medical Students. BMC Medical Education, 18(1), 47. https://doi.org/10.1186/ s12909-018-1165-7

Agustina, N. (2018). Perkembangan Peserta Didik. Yogyakarta: Deepublish.

Ali, M., \& Asrori, M. (2005). Psikologi Remaja dan Perkembangan Peserta Didik. Bandung: Bumi Aksara.

Artha, N. M. W. I., \& Supriyadi, S. (2013). Hubungan antara Kecerdasan Emosi dan Self Efficacy dalam Pemecahan Masalah Penyesuaian Diri Remaja Awal. Jurnal Psikologi Udayana, 1(1), 190-202. https://doi.org/10.24843/ jpu.v1i1.25078

Ates, A. (2019). The Impact of the Emotional Intelligence of Learners of Turkish as A Foreign Language on Reading Comprehension Skills and Reading Anxiety. Universal Journal of Educational Research, 7(2), 571579.

Boynton-Jarrett, R., Rosenberg, L., Palmer, J. R., Boggs, D. A., \& Wise, L. A. (2012). Child and Adolescent Abuse in Relation to Obesity in Adulthood: The Black Women's Health Study. PEDIATRICS, 130(2), $245-253$. https://doi.org/10.1542/peds.2011-1554

Cherry, M. G., Fletcher, I., \& O’Sullivan, H. (2013). Exploring The Relationships among Attachment, Emotional Intelligence and Communication. Medical Education, 47(3), 317-325. https://doi.org/10.1111/medu.12115

Desmita, D. (2011). Psikologi Perkembangan Peserta Didik: Panduan bagi Orang tua dan Guru dalam Memahami Psikologi Anak Usia SD, SMP, dan SMA. Bandung: Remaja Rosdakarya.

Dewi, E., Bundu, P., \& Tahmir, S. (2016). The Effect of Emotional Intelligence, Competence and interpersonal Communication on The Performance of Senior High School Teachers through Achievement Motivation in Makassar, Indonesia. The New Educational Review, 44(2), 176-183. https://doi.org/10.15804/ tner.2016.44.2.14 
Difa, S. F. (2016). Pengaruh Kecerdasan Emosi dan Dukungan Sosial terhadap Resiliensi Mahasiswa Perantau UIN Syarif Hidayatullah Jakarta. Tazkiya: Journal of Psychology, 4(2), 77-97.

Estiane, U. (2015). Pengaruh Dukungan Sosial Sahabat terhadap Penyesuaian Sosial Mahasiswa Baru di Lingkungan Perguruan Tinggi. Jurnal Psikologi Klinis dan Kesehatan Mental, 4(1), 29-40.

Farkhaeeni, A. (2011). Pengaruh Kecerdasan Emosional Terhadap Konsep Diri pada Mahasiswa Fakultas Psikologi UIN Jakarta. (Skripsi tidak diterbitkan). UIN Syarif Hidayatullah.

Handono, O. T., \& Bashori, K. (2013). Hubungan antara Penyesuaian Diri dan Dukungan Sosial terhadap Stres Lingkungan pada Santri Baru. Empathy, 1(2), 79-89.

Hansen, J. C. (1984). The Measurement of Vocational Interests: Issues and Future Directions. Dalam Brown, S. D. \& Lent, R. L. (Ed.), Handbook of Counseling Psychology.

Iflah, I., \& Listyasari, W. D. (2013). Gambaran Penyesuaian Diri Mahasiswa Baru. JPPP - Jurnal Penelitian Dan Pengukuran Psikologi, 2(1), 33-36. https://doi.org/10.21009/JPPP.021.05

Kumalasari, F., \& Ahyani, L. N. (2012). Hubungan antara Dukungan Sosial dengan Penyesuaian Diri Remaja di Panti Asuhan. Jurnal Psikologi: PITUTUR, 1(1), 19-28.

Lusiawati. (2013). Kecerdasan Emosi dan Penyesuaian Diri pada Remaja Awal yang Tinggal di Panti Asuhan Uswatun Hasanah Samarinda. EJournal Psikologi, 1(2), 167-176.

Nisa, K. Y. (2017). Hubungan Kecerdasan sosial dan Kepercayaan Diri dengan Penyesuaian Diri pada Mahasantri Mabna Umти Salamah UIN Malang. (Skripsi tidak diterbitkan). Universitas Islam Negeri Maulana Malik Ibrahim.

Nurfitriana, P. (2016). Penyesuaian Diri pada Mahasiswa Tahun Pertama di Fakultas Psikologi Universitas Muhammadiyah Surakarta. (Skripsi tidak diterbitkan). Universitas Muhammadiyah Surakarta.

Prima, N. R., \& Indrawati, E. S. (2018). Hubungan antara Kecerdasan Spiritual dengan Penyesuaian Diri pada Mahasiswa Tahun Pertama di Fakultas Sains dan Matematika UNDIP. Empati, 7(3), 259-264.

Schoon, I., Parsons, S., \& Sacker, A. (2004). Socioeconomic Adversity, Educational Resilience, and Subsequent Levels of Adult Adaptation. Journal of Adolescent Research, 19(4), 383-404. https://doi. org $/ 10.1177 / 0743558403258856$

Suharyat, Y. (2009). Hubungan antara Sikap, Minat dan Perilaku Manusia. Jurnal Region, 1(3), 1-19.

Webster-Stratton, C., Rinaldi, J., \& Reid, J. M. (2011). Long-Term Outcomes of Incredible Years Parenting Program: Predictors of Adolescent Adjustment*. Child and Adolescent Mental Health, 16(1), 38-46. https:// doi.org/10.1111/j.1475-3588.2010.00576.x

Wibowo, M. E. (2019). Konselor Profesional Abad 21. Semarang: Unnes press.

Yusuf L N, S., \& Sugandhi, N. M. (2011). Perkembangan Peserta Didik. Jakarta: Raja Grafindo Persada.

Zhu, B., Chen, C.-R., Shi, Z.-Y., Liang, H.-X., \& Liu, B. (2016). Mediating Effect of Self-Efficacy in Relationship between Emotional Intelligence and Clinical Communication Competency of Nurses. International Journal of Nursing Sciences, 3(2), 162-168. https://doi.org/10.1016/j.ijnss.2016.04.003

Zubaidi, M. (2016). Penyesuaian Diri pada Mahasiswa Salah Jurusan. (Skripsi tidak diterbitkan). Universitas Islam Negeri Sunan Kalijaga 